\section{The Great TEM Grid Debate: Dull Versus Shiny}

A perennial favorite debate among TEM users is which side of the grid to use, the dull side or the shiny side. This question popped up again on the Microscopy listserver, and received several well-informed replies. In the past, the answer has typically been "whichever works" or "Well, I learned it this way". Now opinion seems to be leaning towards a particular side. Read on for the answers:

From John Bozzola, Director, Center for Electron Microscopy, Southern Illinois University:

This is a good basic question - one that many microscopists have asked when coating grids with various plastic substrates. This question has even been studied in a scientific manner over the years, and the conclusion has generally been that the dull side appears to hold on to the film more tenaciously than the shiny side. Now, I must admit that I started out using the shiny side and resisted going dull for many years (in reference to grids, not sense of humor). I finally did a test and found that there was less drift and better film adhesion on the dull side.

Now a caveat: examine carefully the two sides of the grids and check if there are noticeable burrs or curvature to the grids (especially the latter). You should place the plastic film so that it is in maximal contact with the grid. So, if the grid is slightly bent, make sure the film goes on the convex side. Reason: on the concave side, the film is suspended over the concavity and you will get a lot of drift. I have noticed that some slot grids have such a concavity and, in this case, it may require you to place the film on the "shiny" side.

So, generally speaking, place the film on the dull side of the grid unless the grid is dished or bent. In order to further facilitate adhesion of the film, somee people place a drop of diluted plastic (like Formvar at $0.02 \%$ ) on top of gridsō while on a filter paper. When dried, the thin plastic film has an affinity for the $\overrightarrow{0}$ substrate or film that you finally place onto the grid for supporting sections, etc. From Chuck Garber, President of SPI:

This is certainly the most often asked question about TEM grids, at leaston for our firm, from customers writing or calling in for "advice". After being involvedo for more than thirty years with this question, I have come to the following conclu- $\frac{0}{x}$ sions. I present them here for whatever peer review might be forthcoming:

a) It seems to be about 50/50 (non-scientifically determined) on a worldwide basis as to whether users prefer dull or shiny.

b) While the "dull" side has sharper "protrusions" and, in theory at least, shouli initiate tears and cracks more readily than the shiny side, I am not sure we ouro selves have ever found evidence that is the case. Those expressing preferenceş for the dull side tend to claim better adhesion because of the larger surface areक. available for adhesion. So we have ourselves given up on using our own goode common sense to rationalize which side is "better". We think that one can, ir is general, get comparable results from either side.

c) However, not all grids are manufactured using the same processes and the conclusions drawn from grids from one source might not necessarily be applied to grids from other sources. For example, anyone who has used different "brands" of grids knows that there is a difference between dull and shiny side discrimination. We have even found customers who have expressed a preference for grids showing the least dull/shiny difference so it is not necessarily even a case of good vs. bad.

d) We ourselves believe that the real point of the dull vs. shiny side is to quickly and easily discriminate between which side is "up" and which side is "down", since many samples are not easily seen with the naked eye. Some percentage

\title{
EMITECH
}

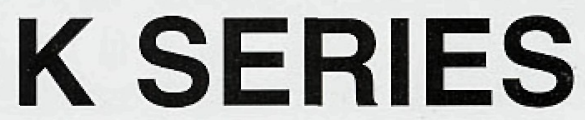

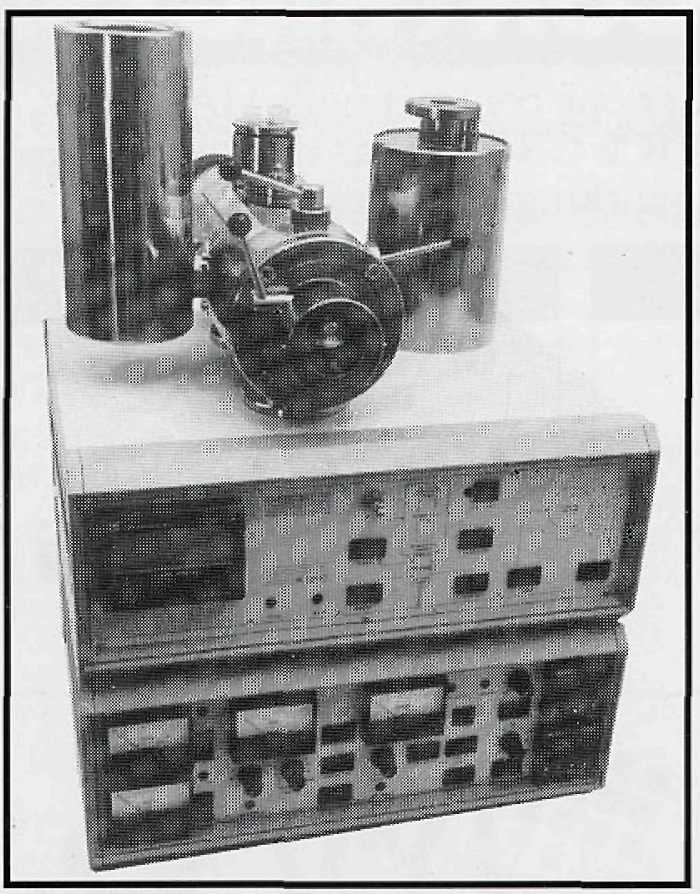

The K1250 System with Unique Cylinder Preparation Chamber and Turbomolecular Pumping Unit

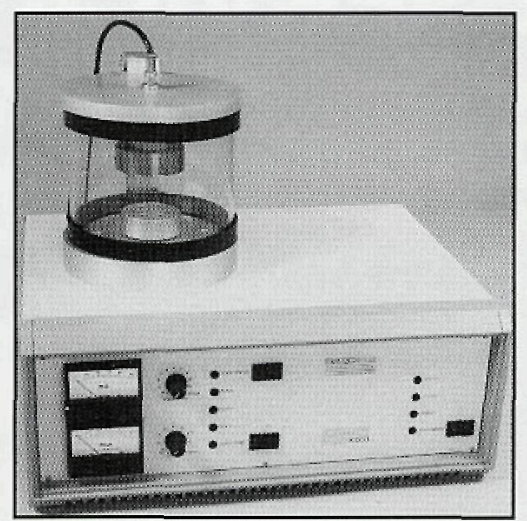

The K550 Automatic Coater

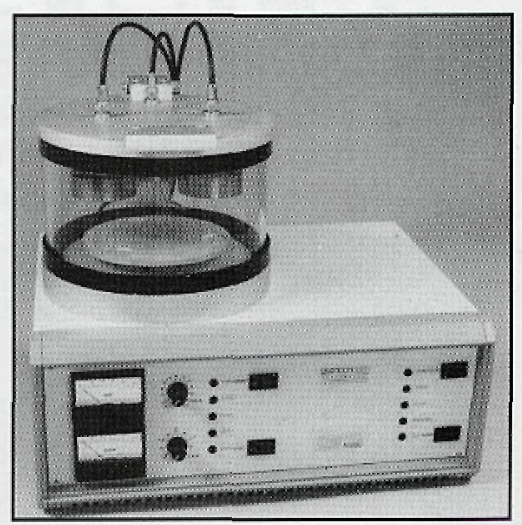

The K650 Automatic Coater
EMITECH OFFERS A FULL LINE OF SPECIMEN PREPARATION EQUIPMENT INCLUDING SPUTTER COATERS, TURBO SPUTTER COATERS, EVAPORATORS, FREEZE DRIERS, CPD'S AND CRYOGENIC SYSTEMS WITH A 2 YEAR WARRANTY ON ALL SYSTEMS.

\section{EMITECH USA, INC.}

Tel: 800/444-3137 • Fax: 281/893-8443

www.emitechusa.com・Email:emitech@ix.netcom.com 
of the population develop a level of color-blindness. This is also true as we get older and, as that happens, there also seems to be a loss in ability to discriminate between dull vs. shiny. Hence, some grids are actually purchased on that basis alone, without regard to any other considerations. From that perspective, it does not matter which side is being used, just so one is consistent and always using the same side for their specimens.

e) Paul Webster raises an interesting question relative to there being an asymmetry. He called it a polarity to the slot grids. We ourselves have never looked at that aspect of the issue before. But if it is correct, then it would probably also apply to the use of aperture grids as well, since they are made under identical conditions. In general, it is the shiny side that is the one in contact with the "glass master" during the grid making, and the dull side is the one that "grows" out into the plating bath. In any case, the point is well made and this will encourage us to see what could be done to reduce the asymmetry present in slot grids.

All of my comments, and I presume those of the others, are directed specifically for those grids that are electro-deposited, that is, $\mathrm{Cu}, \mathrm{Ni}$, and $\mathrm{Au}$, and such comments would not be applicable to grids made by other methods (for example, chemical etching, to produce grids from $B$ or $W$, etc.).

From Sara F. Miller, Duke University Medical Center:

We routinely use the dull side, not only because of the increased "stickiness" of the membrane to the rough surface, but also because if the film is put on the shiny side and then coated it with carbon as we always do, there are 2 dull sides. It is, thus, more difficult to determine where the sample is when the grid flips over - particularly if you're doing negative stains. This may not be the case for cryosections in methyl cellulose or epoxy sections but, to be consistent, we always use the dull side for these too.

From Paul Webster, House Ear Institute, Los Angeles:

The trivial answer to this question is that all experts are correct. Therefore either side is good. However, there is one instance where I have found this to be incorrect. Single slot grids have a polarity to them. The dull side has rounded edges, whereas the shiny side is completely flat. Check it out. The immediate consequence is that if formvar is applied to the dull side, it will eventually sag into the hole and stick to the support you store it on. On the shiny, flat side, this is not a problem. This might be true for the mesh grids too. I can't say more on this because I never looked.

For the record, for routine use I usually put the film on the dull side too and have never had a problem. I know a colleague who swears that using the shiny side is best because it improves resolution! I do know that if the film has been damaged in some way, buffers will react with the metal. Hence the dogma of not using copper grids for immunocytochemistry. My advice is to believe all the experts and do whatever you want. Even better, become an expert and make everyone in your lab do it your way!

One final thought on this: interference colors, which reveal the location of sections on the grid, are more easily seen on a dull background. Interference colors also play an important role in the evaluation of support film thickness during the final, drying step in cryosectioning. There is a reason for choosing one side after all.

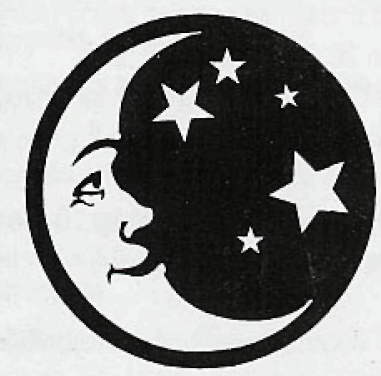

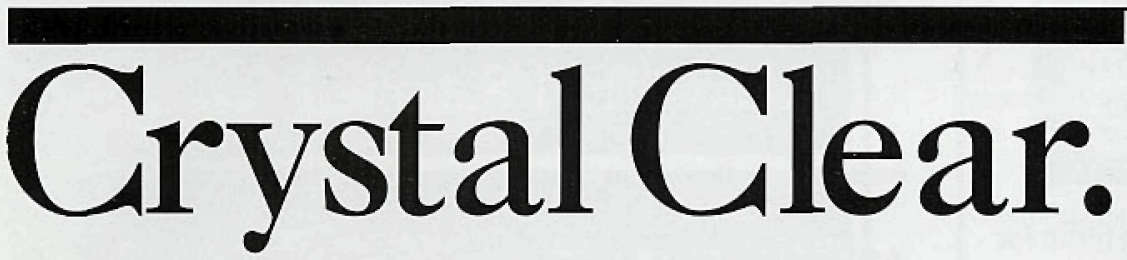

\section{The Meiji EM Series of Modular Stereo Mieroscopes.}

If you are looking for precision, durability, quality and value in a stereo microscope, we invite you to take a closer look at Meiji's EM Series of Stereo Microscopes.

The modular design (A wide variety of bodies, single magnification or zoom - rotatable $360^{\circ}$, auxiliary lenses, eyepieces, stands, holders, etc.) gives you the freedom to create the ideal instrument for your specific needs or application, and Meiji stands behind every instrument with its limited Lifetime Warranty.

For more information on these economically priced stereo microscopes, please call, FAX or write us today.

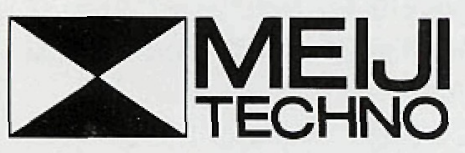

\section{MEIJI TECHNO AMERICA}

2186 Bering Drive, San Jose, CA 95131, Toll Free Telephone: $\mathbf{8 0 0 . 8 3 2 . 0 0 6 0}$ FAX: 408.428.0472, Tel: 408.428.9654 